\title{
BREVE REPASO: LA LEGÍTIMA DEFENSA EN NUESTRO ORDENAMIENTO ACTUAL Y SU UTILIZACIÓN COMO FUNDAMENTO DE LA OPOSICIÓN A LA FORMALIZACIÓN
}

\author{
BRIEF REVIEW: LEGITIMATE DEFENSE IN OUR \\ CURRENT SYSTEM AND ITS USE AS A BASIS FOR \\ OPPOSITION TO FORMALIZATION
}

\section{BREVE REVISÃO: A LEGÍTIMA DEFESA EM NOSSO ORDENAMENTO ATUAL E SUA UTILIZAÇÃO COMO FUNDAMENTO DA OPOSIÇÃO À FORMALIZAÇÃO}

\author{
ALEJANDRA DOMÍNGUEZ ${ }^{1}$ Y EVANGELINA TORRES GUGELMEIER ${ }^{2}$
}

RECIBIDO: $28 / 10 / 2020$

ACEPTADO: 8/12/2020

RESUMEN: en el presente trabajo realizamos un repaso de las modificaciones introducidas por la Ley de Urgente Consideración en el concepto de legítima defensa. Referimos especialmente a las presunciones establecidas por la nueva redacción así como el alcance de las mismas. Finalmente analizamos la formalización de la investigación en nuestro no tan nuevo sistema adversarial, la posibilidad de oponerse a la misma y la viabilidad de que el fundamento radique en la existencia de una legítima defensa como causa de justificación. En función a ello analizamos los distintos estándares probatorios que existen en las distintas etapas de la audiencia de formalización y los argumentos por los cuales entendemos que el análisis de las cuestiones de hecho en las que eventualmente se funde una legítima defensa no pueden ser tratadas en esta etapa procesal de formalización.

PALABRAS CLAVE: sistema penal acusatorio, causa de justificación, legítima defensa, presunción simple, formalización, estándar probatorio.

ABSTRACT: In this paper, we review the modifications introduced by the Urgent Consideration Law in the concept of legitimate defense. We refer especially to the assumptions established by this law as well as their scope. Finally we analyze the forma-

1 Fiscal Letrada Departamental. ORCID ID: https:// orcid.org/0000-0002-0953-176X. mariaala_29@hotmail.com

2 Fiscal Letrada Adscripta. ORCID ID: https:/ / orcid.org/0000-0002-3912-6810 etorres@correo.um.edu.uy 
lization of the investigation in our not so new adversarial system, and the possibility of the defense to oppose and the viability to found that opposition in the existence of the legitimate defense as a justification cause. Based on this, we analyze the different evidentiary standards that exist in the different stages of the formalization hearing and the arguments by which we understand that the analysis of the factual issues on which a legitimate defense is eventually based, cannot be dealt in this procedural stage of formalization.

KEY WORDS: adversarial system, justification cause, legitimate defense, simple assumptions, formalization, evidentiary standard.

RESUMO: no presente trabalho realizamos uma revisão das modificações introduzidas pela Lei de Urgente Consideração no conceito de legítima defesa. Referimos, especialmente, às presunções estabelecidas pela nova redação, bem como o alcance das mesmas. Finalmente, analisamos a formalização da investigação, no nosso não tão novo sistema adversarial, a possibilidade de se opor à mesma e a viabilidade de que o fundamento se estabeleça na existência de uma legítima defesa como causa de justificação. Em função disso, analisamos os diferentes padrões probatórios que existem nas diferentes etapas da audiência de formalização e os argumentos pelos quais entendemos que a análise das questões de fato, nas que eventualmente se fundamenta uma legítima defesa, não podem ser tratadas nesta fase processual de formalização.

PALAVRAS - CHAVE: sistema penal acusatório, causa de justificação, legítima defesa, presunção simples, formalização, standard probatório.

\section{Introducción}

De acuerdo a lo previsto en el Título II, Capítulo I del Código Penal la legítima defensa constituye en nuestro ordenamiento una de las causas de justificación que en caso de configuración eximen de responsabilidad al sujeto indicado como responsable del delito.

La redacción original del art. 26 del Código Penal ha sido objeto de diversas modificaciones introducidas en primer lugar por el art. 66 de la Ley $\mathrm{N}^{\mathrm{o}} 17.243$ de fecha 29 de junio de 2000 y recientemente por el art. 1 de la Ley $N^{\circ} 19.889$ de fecha 9 de julio de 2020 denominada "Ley de Urgente Consideración" vigente a partir del 24 de julio de 2020.

Con esta nueva norma se introdujeron importantes cambios a la redacción anterior y al igual que en las modificaciones realizadas en el año 2000, 20 años después vuelve a ser objeto de debate la introducción de situaciones que a texto expreso se reputan como legítima defensa presunta.

Es respecto a estas nuevas introducciones legislativas que nos interesa ahondar en el alcance de las mismas. A tales efectos abordaremos brevemente el concepto de esta causa de justificación así como el alcance de las modificaciones introducidas, en especial, de las nuevas presunciones incorporadas por la Ley de Urgente Consideración (en adelante "la LUC"). 
Finalmente y atento a que se han visto casos en la práctica en los que la defensa invoca como fundamento para la oposición a la formalización la existencia de una supuesta situación de legítima defensa, abordaremos también este tema. En efecto, analizaremos brevemente el concepto de formalización en nuestro sistema procesal penal actual (art. 266 del Código del Proceso Penal de 2017) para luego analizar si la existencia de una legítima defensa es argumento hábil para fundar una eventual oposición a la formalización.

\section{La legítima defensa como causa de justificación}

Desde tiempo inmemorial se ha sostenido que "la legitima defensa no tiene historia", significando con ello que en las más remotas civilizaciones ya existían referencias a la licitud de la muerte del agresor injusto en nombre de la defensa legítima. Jiménez de Asúa, relata que diversos autores y códigos del Siglo XIX y de las primeras décadas del Siglo $X X$, se referían a esas circunstancias como "eximentes", "causas de inimputabilidad" o "causas de inculpabilidad". ${ }^{3}$

Conforme señala Lombardi, los códigos penales modernos son contestes en cuanto a que la legítima defensa es una causa de justificación que excluye el carácter antijurídico de una conducta típica, actuada en las circunstancias que allí se describen.

En nuestro país, desde la aprobación en 1934 de nuestro Código Penal el legislador reguló la legítima defensa como causa de justificación, en sintonía con la doctrina imperante.

Como señala Langón "Quien actúa justificadamente adecua su comportamiento al derecho, no lo viola, sino que antes bien lo cumple, siendo su conducta ajustada a la norma, que no puede al mismo tiempo, por un lado prohibir y por otro, permitir la acción. En estos casos, como dice la propia ley, se "justifica" una conducta típica, ya sea permitiéndola (como en el caso del estado de necesidad o de legítima defensa), o imponiéndola (como en situación de cumplimiento de la ley)". ${ }^{4}$

A continuación, referiremos a la legítima defensa como causa de justificación en nuestro ordenamiento.

\section{La regulación de la legítima defensa en nuestro ordenamiento}

\subsection{Evolución legislativa}

La redacción original del art. 26 del Código Penal ha sido objeto de diversas modificaciones introducidas en primer lugar por el art. 66 de la Ley $\mathrm{N}^{\mathrm{o}} 17.243$ de fecha 29 de junio de 2000 y recientemente por el art. 1 de la LUC.

Antes de su última modificación el art 26 del CP establecía:

"Se halla exento de responsabilidad:

3 Referencias extraídas de Jornada del Colegio de Abogados del 22 de mayo de 2012 aportada por E. Lombardi.

4 LANGÓN, Miguel, “Código Penal Uruguayo y Leyes Complementarias Comentados", Ed. UM, Segunda Edición Actualizada, año 2018, Pág. 90. 
1. El que obra en defensa de su persona o derechos, o de la persona o derechos de otro, siempre que concurran las circunstancias siguientes:

A) Agresión ilegítima.

B) Necesidad racional del medio empleado para repelerla o impedir el daño.

C) Falta de provocación suficiente por parte del que se defiende.

Se entenderá que concurren estas tres circunstancias respecto de aquél que defiende la entrada de una casa habitada o de sus dependencias, o emplea violencia contra el individuo extraño a ella que es sorprendido dentro de la casa o de las dependencias.

2. El tercer requisito no es necesario tratándose de la defensa de los parientes consanguíneos en toda la línea recta y en la colateral hasta el segundo grado inclusive, del cónyuge, de los padres o hijos naturales reconocidos o adoptivos, siempre que el defensor no haya tomado parte en la provocación.

3. El que obra en defensa de la persona o derechos de un extraño, siempre que concurran las circunstancias expresadas en el numeral 1 y la de que el defensor no sea impulsado por la venganza, resentimiento $u$ otro motivo ilegítimo.

A partir de la entrada en vigencia de la LUC se introdujeron modificaciones al régimen legal de la legítima defensa. Estos cambios incluyeron aclaraciones en cuestiones que permitían opiniones encontradas de los operadores, y asimismo, se establecieron presunciones de legítima defensa que con anterioridad, no estaban establecidas.

A continuación, analizaremos dichos cambios sin perjuicio de referir previamente a las justificaciones manejadas a nivel del Parlamento para la introducción de dichas modificaciones.

\subsection{La justificación de las modificaciones propuestas en la LUC}

Si bien se verá que la legítima defensa no fue modificada en cuanto a los elementos requeridos para su configuración, a partir de la nueva redacción dada por la LUC se incorporaron cambios sustanciales que inciden directamente en la aplicación práctica de este instituto.

Las modificaciones introducidas en la LUC respecto a la legítima defensa, no responden a una iniciativa nueva. Al tiempo de presentada la LUC para su aprobación, ya existían otros proyectos en similar sentido a las modificaciones propuestas en la LUC. ${ }^{5}$ Según surge de las discusiones parlamentarias, dichos proyectos fueron considerados en el proceso de elaboración de la LUC.

5 Proyecto de ley sobre legítima defensa presentado por el entonces senador Gallinal del año 2011, proyecto de reformulación de la legítima defensa del exdiputado José Amy del año 2012, iniciativa presentada por el exsenador Pedro Bordaberry en el año 2015 y a aquella presentada por varios legisladores del Partido Nacional en el año 2016, el proyecto de ley del exsenador Luis Alberto Heber del año 2017. 
En la sesión celebrada el día 4 de mayo de 2020 por la Comisión Especial para el Estudio del Proyecto de Ley con Declaratoria de Urgente Consideración, estando en sesión el Ministro del Interior Jorge Larrañaga se señaló que el país estaba atravesando una situación de emergencia en materia de seguridad. Señaló además que lo que movía a los cambios propuestos era un cambio de paradigma. Concretamente el Sr. Ministro señaló: "Nosotros sentimos que durante los últimos tiempos, durante los últimos años, se fue perdiendo el respeto por la autoridad, en buena parte, el respeto por la policía, como soporte de la autoridad pública. Ha habido una presunción política e ideológica en contra de la policía, una presunción en contra de quien ejerce la autoridad. (...) Siempre hemos dicho, lo dijimos, lo mantenemos, lo reafirmamos, lo apoyamos y lo vamos a llevar adelante: hay que cuidar a los que nos cuidan. Esto es fundamental. $Y$ este proyecto apunta a recuperar la presunción a favor del buen funcionario policial, que es de lo que se trata."

En el Capítulo destinado a la Seguridad Pública se advierte una clara intención de respaldo al actuar policial por parte del legislador. Refiriéndose a las modificaciones propuestas al art. 26 del Código Penal, el Subsecretario del Ministerio del Interior reconoció en Sesión de la Comisión que con las modificaciones se buscó "(...) introducir pautas que permitan objetivar la apreciación de la defensa del ataque no habilitado, descartando de plano-porque no es la intención-hablar de gatillo fácil, pero dando preferencia a la protección legal de la víctima frente al agresor o victimario, extendiendo, por lo tanto, la legítima defensa presunta prevista en la normativa".

Con base en estos argumentos se justificó ante el Parlamento la necesidad de profundizar en la definición legal de la legítima defensa para adecuar la redacción de la norma a una realidad que ya no es la de 1934 .

\subsection{Las modificaciones introducidas por la LUC en el art. 26 del Código Penal}

Con base en los fundamentos ya señalados a partir del 24 de julio de 2020 y producto de la última modificación introducida por el art. 1 de la Ley $\mathrm{N}^{\mathrm{O}} 19.889$, el art 26 del CP establece:

"Se halla exento de responsabilidad el que obra en defensa de su persona o derechos, o de la persona o derechos de otro, siempre que concurran las circunstancias siguientes:

A) Agresión ilegítima.

B) Necesidad racional del medio empleado para repelerla o impedir el daño.

El medio se considerará racional cuando resulte ser una respuesta suficiente y adecuada a fin de conjurar el peligro derivado de la agresión sufrida.

Cuando la defensa deba ser ejercida respecto de cualquier derecho de contenido patrimonial, la racionalidad deberá ser apreciada con prescindencia de que no haya existido o ya hubiera cesado una agresión física a la persona que se defiende.

C) Falta de provocación suficiente por parte del que se defiende. 
El tercer requisito no es necesario tratándose de la defensa de los parientes consanguíneos en toda la linea recta y en la colateral hasta el segundo grado inclusive, del cónyuge o concubino, o de los padres o hijos adoptivos, siempre que el defensor no haya tomado parte en la provocación.

Se entenderá que concurren estas tres circunstancias respecto de:

I) Aquel que defiende la entrada de una casa habitada o de sus dependencias, o emplea violencia contra el individuo extraño a ella que es sorprendido dentro de la casa o de las dependencias.

Se considerarán dependencias de la casa, en las zonas urbanas: los balcones, terrazas, azoteas, parrilleros, barbacoas, jardines, garajes y cocheras o similares, siempre que tengan una razonable proximidad con la vivienda.

Además, se considerarán dependencias de la casa en zonas suburbanas o rurales: los galpones, instalaciones o similares que formen parte del establecimiento, siempre que tengan una razonable proximidad con la vivienda.

II) El funcionario del Ministerio del Interior o del Ministerio de Defensa Nacional que, en ocasión o con motivo del cumplimiento de sus funciones, repele una agresión física o armada contra él o un tercero, empleando las armas o cualquier otro medio de defensa en forma racional, proporcional y progresiva, en cuanto eso sea posible, y en las mismas circunstancias agote previamente los medios disuasivos que tenga a su alcance, sin perjuicio de la prueba en contrario.

III) Aquel que repele el ingreso de personas extrañas, con violencia o amenazas en las cosas o personas o con la generación de una situación de peligro para la vida o demás derechos, en un establecimiento que desarrolle actividad comercial, industrial o agraria en los términos establecidos por el artículo $3^{\circ}$ de la Ley $N^{\circ} 17.777$, de 21 de mayo de 2004.

La nueva redacción incorporó a la norma algunos conceptos con implicancias prácticas muy relevantes.

En primer lugar, la actual redacción aporta una modificación sustancial en cuanto fija criterios para la interpretación del elemento de la necesidad racional del medio empleado para repeler la agresión ilegítima o impedir el daño. En efecto, la nueva redacción establece que el medio se considerará racional cuando resulte ser una repuesta suficiente y adecuada a fin de conjurar el peligro derivado de la agresión sufrida.

Asimismo, referido a la interpretación del elemento de la racionalidad del medio empleado en la nueva redacción se establece que: "Cuando la defensa deba ser ejercida respecto de cualquier derecho de contenido patrimonial, la racionalidad deberá ser apreciada con prescindencia de que no haya existido o ya hubiera cesado una agresión física a la persona que se defiende".

Este nuevo inciso refiere expresamente a la legítima defensa de derechos de contenido patrimonial desligándola de la necesidad de que haya existido o ya hubiera cesado una eventual agresión física. De esta forma estando al tenor literal de la norma, en casos de legítima defensa para defender derechos de contenido patrimonial y para apreciar el 
elemento de la "racionalidad del medio empleado" no se requiere -como se exigía por algunos operadores judiciales- la agresión previa o simultánea de la persona.

De todas formas, se entiende que el requisito de la racionalidad debe permanecer y será ahora el elemento clave para la interpretación de esta figura aún en casos de legítima defensa de derechos de contenido patrimonial.

Como se señaló por el Subsecretario del Ministerio del Interior en sesión de la Comisión "(...) la correcta apreciación de este concepto va de la mano de la racionalidad, que va a permitir descartar si alguien va más allá de lo previsto por la norma, pero en cambio va a amparar, por ejemplo, a quien lo hace para evitar el robo del producido en varias jornadas de trabajo, que es el sueldo para mantener a su familia o el dinero destinado para el pago de los sueldos de sus trabajadores".

Otra de las modificaciones introducidas por la LUC se relaciona con el tercer requisito exigido para la configuración de la legítima defensa: la falta de provocación suficiente por parte del que se defiende. En relación a este elemento se incorpora la referencia expresa al concubino, equiparando por vía legislativa este concepto al de cónyuge.

Por otra parte, la LUC elimina el numeral 3 final del art. 26 del Código Penal que refería a "El que obra en defensa de la persona o derechos de un extraño, siempre que concurran las circunstancias expresadas en el numeral 1 y la que el defensor no sea impulsado por venganza, resentimiento u otro motivo ilegítimo".

Quizás la modificación más trascendente que fue incorporada al art. 26 del Código Penal, radica en la incorporación de presunciones, en las que se entiende concurren los tres requisitos de la legítima defensa enumerados en los literales A a C del artículo.

Dada la trascendencia de la incorporación legislativa realizada en la LUC trataremos este punto en el apartado siguiente.

\subsection{Acerca de las presunciones incorporadas por el artículo 1 de la ley 19.889 al art. 26 del Código Penal}

Con base en lo señalado en la exposición de motivos de la LUC en cuanto al aumento de los índices de criminalidad en la sociedad, así como al incremento de la violencia empleada por los delincuentes en la comisión de los delitos sobre las personas y sus derechos y a la necesidad de consagrar mayores y mejores garantías para el cumplimiento de la función policial, en la actual redacción se incorporaron algunos incisos que vale la pena analizar separadamente.

Se trata de presunciones mediante las cuales el legislador pretendió introducir pautas que permitieran objetivar la apreciación de los casos de defensa del ataque no habilitado. Así lo expresó el Subsecretario del Ministerio del Interior Guillermo Maciel en sesión de la Comisión ante el Parlamento. 
En primer lugar se incorpora el numeral I) que establece que se considera que concurren los tres requisitos previstos para la configuración de la legítima defensa (literales A a C) respecto de aquel que defiende la entrada de una casa habitada o de sus dependencias, o emplea violencia contra el individuo extraño a ella que es sorprendido dentro de la casa o de las dependencias.

Respecto a esta incorporación estando en sesión ante la Comisión el Subsecretario del Ministerio del Interior Sr. Guillermo Maciel señaló que ya en el Código Penal de 1933 Irureta Goyena había ampliado el criterio de legítima defensa a la defensa de los derechos entendiéndose por tales los previstos en el artículo 7 de la Constitución. En efecto, en Comisión se señaló que "(...) algunos operadores judiciales descartan que una persona en defensa, por ejemplo, de su propiedad, pueda racionalmente -esta es la clave del artículo, actuar con racionalidad, la cual va a medir, entender y evaluar el juez-ejercer su defensa contra la persona del delincuente, cuando el accionar de este no ha puesto en peligro su vida o integridad física, pero sí hay que reparar en que también podrá hacerlo para impedir el daño, o sea, los derechos".

Nuevamente es clave para la interpretación práctica de esta presunción el análisis casuístico del requisito de la racionalidad.

Asimismo, con la incorporación de este numeral I) la LUC aportó una definición expresa en lo que refiere al concepto de dependencias del hogar, cuestión que generaba discrepancias a nivel doctrinario y jurisprudencial. A partir de esta incorporación el legislador considera como dependencias de la casa en las zonas urbanas a los balcones, terrazas, azoteas, parrilleros, barbacoas, jardines, garajes y cocheras o similares siempre que mantengan proximidad razonable con la vivienda. Por su parte, para el caso de dependencias de la casa en zonas suburbanas o rurales, se considerarán tales los galpones, instalaciones o similares que formen parte del establecimiento, siempre que tengan una razonable proximidad con la vivienda.

Por otra parte, con la LUC se incorporó el numeral II) en el art. 26 del Código Penal que establece una presunción de legítima defensa policial para funcionarios del Ministerio del Interior o del Ministerio de Defensa que en ocasión o con motivo del cumplimiento de sus funciones repelen una agresión física o armada contra él o un tercero, empleando las armas o cualquier otro medio de defensa en forma racional, proporcional y progresiva, en cuanto eso sea posible, y en las mismas circunstancias agote previamente los medios disuasivos que tenga a su alcance sin perjuicio de la prueba en contrario.

Se trata de una presunción de legítima defensa para el personal que ejerce función policial. Al exponer en sesión de la Comisión, el Subsecretario del Ministerio del Interior Guillermo Maciel señaló que lo que se pretendió fue "consagrar mayores y mejores garantías para el cumplimiento de la función policial, estableciendo una presunción simple de la legítima defensa policial, que, obviamente, admite prueba en contrario. Se trata de una norma que trata de amparar a los funcionarios en cumplimiento del deber, expuestos a una delincuencia cada vez más violenta y agresiva, que no duda en disparar y en poner en riesgo la vida de terceros y de los propios policías". 
Nuevamente el elemento de la racionalidad y progresión resultarán claves. Su análisis será obligatorio en cada caso concreto para entender acerca de la aplicación de esta causa de justificación.

Finalmente la LUC incorpora al art. 26 del Código Penal el numeral III) aportando otra presunción simple en cuanto se considera legítima defensa la conducta de quien repele el ingreso de personas extrañas con violencia o amenazas en las cosas o personas o con la generación de una situación de peligro para la vida o demás derechos, en un establecimiento que desarrolle actividad comercial, industrial o agraria. ${ }^{6}$

\section{Alcance de las presunciones incorporadas al art. 26 del Código Penal por el art. $1^{\circ}$ de la LUC}

Se considera que las presunciones incorporadas al art. 26 del Código Penal por el art. $1^{\circ}$ de la LUC son presunciones simples que como tales admiten prueba en contrario.

Ya en la redacción anterior se preveía una presunción de legítima defensa y la incorporación de otras nuevas no elimina a nuestro juicio la interpretación en cuanto al carácter relativo de las mismas. Como señala Cairoli, en materia penal deben desterrarse las presunciones absolutas por el peligro que genera el suponer probadas cuestiones sin prueba de descargo. ${ }^{7}$ En el mismo sentido, Bayarado y Camaño Rosa sostenían el carácter simple de las presunciones en relación a la legítima defensa.

Incluso Malet señala que en materia penal la esencialidad que tiene la verdad material no da lugar a la existencia de presunciones legales en esta materia. ${ }^{8}$ Entendemos entonces que las nuevas presunciones al igual que la anterior poseen el carácter de presunción simple que como tal admiten prueba en contrario.

El carácter relativo de las presunciones incorporadas por esta norma implican en la práctica que no toda situación que involucre a un funcionario del Ministerio del Interior o del Ministerio de Defensa, así como de empleados de empresas de seguridad que repelan una agresión en cumplimiento de sus funciones, o de una persona que repela el ingreso de personas extrañas en forma violenta a un establecimiento comercial, industrial o agrario en las condiciones previstas en la ley, caerá por ese solo hecho en un caso de legítima defensa.

Entendemos que las situaciones deberán analizarse caso a caso en función a las circunstancias de hecho que rodearon el caso concreto y en función a dicho análisis determinar si en el caso se cumplen con los elementos requeridos para la configuración de la legítima defensa. Como señalamos el análisis de la racionalidad y progresión serán fundamentales.

En efecto, para la interpretación de las presunciones continúa siendo clave el análisis de los requisitos de la legítima defensa, en especial el actuar racional, el que va a ser

$6 \quad$ Actividad agraria definida según lo dispuesto en el art. 3 de la Ley N. ${ }^{\circ} 17.777$ de fecha 21 de mayo de 2004.

7 CAIROLI, Milton, "El Derecho Penal uruguayo y las nuevas tendencias dogmático penales", Tomo I, "La Ley - El Delito" FCU, $2^{\circ}$ ed. 2001, Pág. 231.

8 MALET, Mariana. "Presunciones en el código penal", FCU, Montevideo, 1995, Pág. 160. 
considerado en primer término por el Fiscal del caso a los efectos de la imputación como resultado de la investigación y luego el juez lo analizará en función a la valoración de las probanzas en el dictado de la sentencia definitiva.

La jurisprudencia ya ha señalado al respecto que deberá estarse en cada caso a la necesidad de la defensa que se justificará cuando el bien atacado sea importante y el peligro que se cierna sobre él sea grave e inminente pero no en los demás casos por más que la ley lo presuma. ${ }^{9}$

Entendemos que el legislador introdujo presunciones relativas que no sólo admiten prueba en contrario sino que implica que para su aplicación a un caso concreto se cumplan con los elementos exigidos para la configuración de la causa de justificación. Como enseña el Profesor Montano, si a la eximente le faltara algún elemento podrá ser considerada como legítima defensa incompleta y en ese caso aplicarse como una atenuante. ${ }^{10}$

\section{La puesta a punto: el concepto de legítima defensa en la redacción actual}

Sin perjuicio del detalle de las modificaciones e incorporaciones introducidas por la LUC al art. 26 del Código Penal entendemos que el concepto de legítima defensa no sufrió modificaciones.

La legítima defensa mantiene aún hoy la necesidad de que se configuren los tres elementos o requisitos: i) la agresión ilegítima; ii) la necesidad racional del medio empleado para repelerla o impedir el daño y iii) la falta de provocación suficiente por parte de quien se defiende.

Con relación al segundo requisito o elemento (necesidad racional del medio empleado para repeler la agresión o impedir el daño), a partir de la nueva redacción del art. 26 del Código Penal aportada por la LUC, se aportan a estos efectos algunos criterios antes inexistentes.

En efecto, en su actual redacción el artículo establece que se considerará racional -refiriéndose al medio- cuando resulte ser una respuesta suficiente y adecuada a fin de conjurar el peligro derivado de la agresión sufrida.

Asimismo se aporta la referencia en cuanto a que la defensa podrá ser ejercida respecto de cualquier derecho de contenido patrimonial en cuyo caso la racionalidad deberá ser apreciada con prescindencia de que no haya existido o ya hubiera cesado una agresión física a la persona que se defiende.

En cuanto a las presunciones, nos remitimos al análisis señalado precedentemente.

9 CAIROLI, Milton, "El Derecho Penal uruguayo y las nuevas tendencias dogmático penales", Tomo I, "La Ley - El Delito" FCU, $2^{\circ}$ ed. 2001, Pág. 234. Cita Sentencia No 180/93 del TAP $3^{\circ}$.

10 MONTANO, Pedro, "Sistema Penal Uruguayo", Montevideo, marzo 2020, Pág. 155. 


\section{La formalización en nuestro sistema procesal penal y la viabilidad de la oposi- ción a la misma en audiencia}

Definido el concepto de la legítima defensa y el alcance de modificaciones previstas en la norma corresponde referir a las aplicaciones prácticas que este instituto puede tener a nivel de los operadores.

Nos pareció interesante referir a la viabilidad de que la Defensa pueda invocar la existencia de una situación de legítima defensa para fundar su oposición a la formalización. Ello debido a que se han visto oposiciones en la práctica fundadas en la existencia de una legítima defensa. Se plantea la interrogante de si es admisible que eventualmente pueda rechazarse la solicitud de formalización ante la invocación de la existencia de una supuesta legítima defensa. O que en su defecto, ante la admisión de la formalización la defensa pueda agraviarse en su apelación alegando la existencia de esta causa de justificación.

En este entendido nos pareció oportuno señalar nuestra opinión en relación a este punto. Para ello en forma previa haremos una breve referencia al concepto de formalización, el estándar probatorio exigido así como la procedencia de la oposición a la misma en nuestro actual sistema procesal penal.

\subsection{La formalización en nuestro sistema procesal penal}

El art 266 del CPP establece que cuando existan "elementos objetivos suficientes" que den cuenta de la comisión de un delito y de la identificación de sus presuntos responsables, el fiscal deberá formalizar la investigación solicitando al juez competente la convocatoria a audiencia de formalización.

Como señala Larrieu, en nuestro sistema la formalización es la comunicación que en audiencia y bajo la presencia del Juez hace la fiscalía al imputado acompañado de su abogado, en la cual le comunica los hechos que se le atribuyen, las evidencias con que se cuentan y la calificación jurídica que se le imputa. En esta instancia los cuestionamientos que se podrán realizar versarán sobre la claridad de los hechos que se narran pero no sobre el fondo del asunto. ${ }^{11}$

Respecto a la manera en que se concibe la formalización en el sistema procesal penal uruguayo si bien es cierto la especial manera en que se regula en la legislación nacional en relación al derecho comparado, la jurisprudencia ya ha señalado que de todas formas "(...) lo lógico en un sistema acusatorio es que el control de la acción persecutoria le corresponde al Ministerio Público y éste decide si ejerce o no la acción, pero una vez que decide ejercerla, lo que hace a través del tribunal es comunicar a la persona y someterla al control jurisdiccional (Arellano, Seminario Internacional, amu.org.uy). De todos modos, (...) el control judicial no debe significar un antejuicio de la culpabilidad exigiendo la demostración de los hechos y participación del imputado como infiere la defensa". ${ }^{2}$

11 LARRIEU, "La actuación del Juez en el Nuevo proceso Penal", en "Estudios Sobre el Nuevo Proceso Penal- Implementación y Puesta en Práctica", FCU, 2018, pág 290.

12 Tribunal de Apelaciones de $1^{\circ}$ Turno, Sentencia N. ${ }^{\circ} 435 / 2020$ de fecha 21 de julio de 2020. 
El Tribunal de Apelaciones en lo Penal de $1^{\circ}$ Turno ha señalado en el comentado fallo que: "En nuestro sistema la formalización de la investigación no supone necesaria o regularmente un pronunciamiento judicial sobre los hechos y la participación del investigado, a la manera del procesamiento". (TAP $1^{\circ}$ Turno sentencia 435/2020).

En relación a este punto es importante destacar que este análisis por parte del juez de garantía deberá realizarse en consideración al estándar probatorio exigido en esta etapa de formalización y no el correspondiente por ejemplo, al juicio oral. Y ello porque hemos visto que en la práctica se han realizado oposiciones a formalizaciones en las que la Defensa exige estándares probatorios superiores equiparando así el estándar probatorio exigido para la formalización con el correspondiente a la etapa de solicitud de medidas cautelares o incluso del juicio oral.

No compartimos este tipo de equiparaciones en tanto refieren claramente a estándares probatorios diversos.

\subsection{Acerca de la oposición a la formalización en nuestro sistema procesal}

Así entendida la formalización en nuestro ordenamiento, la jurisprudencia mayoritaria ha zanjado el debate en cuanto a cuándo es procedente la oposición a la misma. Sobre el punto se entiende por la mayoría de nuestros Tribunales que la oposición a la formalización procede únicamente en casos de atipicidad de las conductas por las que se solicita la formalización y que en caso de oposición no corresponde ingresar al análisis del fondo del asunto. Así se han pronunciado los Tribunales de $1^{\circ}, 2^{\circ}$ y $3^{\circ}$ Turno. $^{13}$

La jurisprudencia ha admitido la oposición a la formalización en hipótesis en que la misma es manifiestamente improponible y ello podrá ocurrir si de la descripción de los hechos resulta imposible que se haya cometido un delito por ser tales hechos atípicos.

Sin perjuicio de ello, como bien lo señala el TAP de $1^{\mathrm{o}}$ Turno la oposición a la formalización en los casos de aparente atipicidad de la conducta "... no significa de modo alguno que la sede actuante deba ingresar a examinar las evidencias con las que cuenta hasta ese momento la Fiscalía, ni que deba evaluar si en función de las mismas podrá arribarse o no a una eventual condena en juicio". (Sentencias No 124/2018 y 435/2020).

No es raro que los contradictorios que se generan en audiencia de formalización respondan en muchos casos a la exigencia por parte de la Defensa de que el órgano acusador aporte mayor evidencia de la imputación prima facie que se pretende realizar en dicha instancia.

Este debate en torno al estándar probatorio requerido en nuestro sistema para la admisión de la solicitud de formalización lleva a discutir si la admisión de la formalización implica certeza o evidencia del hecho imputado y en ese caso con qué grado de rigurosidad le es exigido.

13 Así se pronunció el TAP de $1^{\circ}$ Turno en Sentencias 124/2018, 435/2020. El TAP de $2^{\circ}$ Turno en Sentencia 382/2020 y el TAP de $3^{\circ}$ Turno en Sentencia N. ${ }^{\circ}$ 95/2020. 
Esta cuestión ya se encuentra zanjada en nuestro ordenamiento. La formalización no exige la acreditación del supuesto material requerido por el art. 224 del CPP para la prisión preventiva es decir, semiplena prueba, ni tampoco el estándar propio del juicio oral (art. 142 del CPP).

Ante los argumentos que en algunos casos suele exigir la Defensa en cuanto a que a su juicio las evidencias no son suficientes o que existen elementos que valorados demuestran la improcedencia de la imputación prima facie realizada en sede de formalización, consideramos que este tipo de valoraciones y argumentaciones responden a una etapa posterior: la del juicio oral.

Entendemos que en caso de argumentar la Defensa la existencia de una causa de justificación como puede ser la legítima defensa, tratándose de una cuestión de puro fondo, esto deberá analizarse en el eventual juicio oral y no en una etapa de formalización.

Por otra parte, si bien en dicha etapa de juicio es el órgano acusador quien debe probar los hechos en los que funda su imputación, de existir versiones alternativas y en función a la teoría del caso que pueda edificar la Defensa, es ésta quien deberá acreditar las versiones de hechos alternativas o "coartadas" que pueda invocar en defensa del imputado.

Pero como se señaló ello será para la etapa procesal de juicio oral, no correspondiendo en instancia de formalización el ingreso al fondo del asunto. No resulta admisible que con la oposición a la formalización invocando teorías fácticas alternativas la Defensa pretenda en dicha instancia el ingreso al fondo del asunto exigiendo que en sede de formalización se demuestre la culpabilidad del sujeto cuya formalización se pretende y que en base a ello exija estándares probatorios que no son propios de la etapa procesal en la que se encuentra (formalización).

En esta etapa no corresponde examinar si la prueba sobre la responsabilidad del imputado es suficiente en términos de plenitud porque ello es materia del juicio oral. Así se ha pronunciado la jurisprudencia. En efecto, refiriéndose al control judicial que puede existir en la formalización, el Tribunal de Apelaciones en lo Penal de $1^{\circ}$ Turno ha sostenido en Sentencia $N^{\circ}$ 435/2020 de fecha 21 de julio de 2020 que: "...el control judicial no debe significar un antejuicio de la culpabilidad, exigiendo la demostración de los hechos y participación del imputado como infiere la Defensa."

También se ha pronunciado en este sentido el Tribunal de Apelaciones en lo Penal de $3^{\circ}$ Turno en reciente Sentencia $N^{\circ} 383 / 2020$ de fecha 22 de julio de 2020. En efecto se ha sostenido que de acuerdo a lo preceptuado por el art. 266 del CPP los "elementos objetivos suficientes que den cuenta de la comisión de un delito" implican alcanzar el estándar propio de esta etapa con la probabilidad razonada y razonable de la verificación de una conducta que se adapte plásticamente desde un ensamble de tipicidad, al delito invocado por la Fiscalía.

A nuestro juicio el argumento insoslayable de que el estándar probatorio en etapa de formalización es inferior al exigido para la imposición de la medida cautelar de prisión 
preventiva y aún al estándar de juicio oral, está dado no sólo por lo dispuesto expresamente en el art. 266 del CPP sino que ello está en consonancia con lo dispuesto en otras normas que legislan en ese sentido.

En primer lugar la referencia a "elementos de convicción suficientes" a que refiere el art. 266 dista mucho de lo que se exige en el art. 224 en cuanto exige semiplena prueba o del art. 142 en cuanto exige certeza procesal.

Asimismo, el propio CPP reconoce que no corresponde exigir en esta etapa inicial del proceso una definitiva calificación delictual de los hechos relatados, ya que incluso pueden modificarse al presentar acusación. Así se dispone en el art. 127 del CPP. Es decir, la norma no exige que se realice una definitiva y final calificación delictual en la etapa de formalización.

El argumento de que en esta etapa no es exigible que el Juez de garantía llegue a un nivel de convencimiento propio de un juez de juicio resulta avalado también por lo dispuesto en el art. 265 del CPP en cuanto dispone que la investigación formalizada podrá continuar aún por hasta dos años.

En definitiva del propio CPP surge que en etapa de formalización el estándar exigido es menor a lo que en muchos casos se suele exigir por parte de la Defensa. Es ilustrativo lo dispuesto por el Tribunal de Apelaciones en lo Penal de $2^{\circ}$ Turno en cuanto dispone que: "El Juez de Garantías, debe valorar la razonabilidad del pedido del actor, obviamente en base a lo que se le plantea sin que implique ningún juzgamiento sobre el fondo de la cuestión y, ello, por la sencilla razón de que no se debate en la audiencia de formalización la responsabilidad del sospechoso sino sobre la existencia de los elementos objetivos con que cuenta el actor sobre determinados sucesos acaecidos que describe en su plataforma fáctica (...)". (Sentencia No 382/2020 del 15 de julio de 2020).

\section{La legítima defensa como fundamento de la oposición a la formalización}

Tomando como base los conceptos vertidos precedentemente, entendemos que la oposición a la formalización que eventualmente pueda plantear la Defensa en audiencia, no podrá basarse en la invocación de la existencia de una supuesta legítima defensa.

En primer lugar, porque en dicha instancia procesal no se debate la responsabilidad penal del imputado, sino la existencia de elementos objetivos suficientes que justifiquen la solicitud al juez de tener por formalizada la investigación que la Fiscalía lleva a cabo contra el imputado.

En segundo lugar, porque la invocación de la existencia de una legítima defensa, será la teoría del caso de la Defensa, que deberá defender y acreditar en un eventual juicio oral, aportando para ello los elementos de prueba que considere pertinentes, en la oportunidad procesal oportuna.

En tercer lugar, porque no se trata de una situación de atipicidad, sino de aplicación al caso concreto de una causa de justificación que para su consideración en el caso con- 
creto, deberán probarse los elementos que la componen y justifican su aplicación. La existencia de legítima defensa no excluye la tipicidad de la conducta, sino que refiere a una causa de justificación y por ello no corresponde analizarla en etapa de formalización.

En cuarto lugar, porque debatir en audiencia de formalización las cuestiones que hacen a la configuración de esta causa de justificación, llevará necesariamente, al análisis de cuestiones de fondo que están vedadas en esta etapa procesal.

En un caso de legítima defensa, el análisis del elemento subjetivo es primordial así como de los restantes elementos que la componen. Por el tipo de análisis que deberá realizarse, claramente se refiere a una tarea propia de la etapa de juicio oral. Recordemos que en el actual sistema procesal penal el Juez de Garantías no tiene en etapa de formalización acceso al legajo fiscal -salvo hipótesis previstas en inciso final del art. 264 del CPP- y deberá decidir únicamente en función a las argumentaciones realizadas por las partes mediante oralidad argumentativa. ${ }^{14}$

No parecería adecuado entonces, que el Juez decida acerca de la aplicación o no de una causa de justificación, únicamente en función a lo que las partes le argumentan en audiencia.

Con relación a este punto debemos considerar que durante la vigencia del sistema procesal penal inquisitivo, la jurisprudencia se había pronunciado en cuanto a que la cuestión relativa a la existencia o no de la legítima defensa, debía ser resorte exclusivo de la decisión en la sentencia definitiva. ${ }^{15}$

Los Tribunales han sostenido en pronunciamientos tramitados de acuerdo al anterior sistema, que en los casos en los que existía solicitud de definición "ab initio" respecto a si se cumplen con los requisitos legales para la aplicación de la legítima defensa, la presencia de la misma debía ser en todo caso “(...) palmaria, prístina, sin hesitación, esto es, que no deje lugar a la menor duda sobre su procedencia, ya que de lo contrario el tema debe resolverse en la sentencia definitiva."16

Entendemos que si en el anterior sistema -en el cual el juez tenía acceso a todas las actuaciones al momento del procesamiento- la tendencia jurisprudencial era a no decidir la aplicación de la legítima defensa en la etapa de procesamiento, con mayor razón en este nuevo sistema las solicitudes para debatir estas cuestiones en etapa de formalización no deberían ser de recibo.

Ahora el Juez no conoce el legajo de la Fiscalía, no tiene a su disposición las evidencias y únicamente podrá decidir en cuanto a la solicitud de formalización, con base en las argumentaciones de las partes.

14 El art. 264 del CPP en su inciso final establece: “El legajo de la Fiscalía no podrá ser consultado por el órgano jurisdiccional, salvo en los casos de los artículos 224.1, 272, 273 BIS y 273 TER de este Código.

15 Sentencia N. ${ }^{\circ}$ 151/2016 del TAP $3^{\circ}$ Turno, publicada como caso 208 en la Revista de Derecho Penal N. ${ }^{\circ} 26-2018$, FCU.

16 Sentencia N. ${ }^{\circ}$ 129/2016 del TAP $2^{\circ}$ Turno, publicada como caso 206 en la Revista de Derecho Penal N. ${ }^{\circ} 26$ - 2018, FCU. 
Por otra parte, el hecho de llegar a esa etapa procesal de solicitud de formalización por parte de la representación fiscal, aún cuando la Defensa se oponga a la misma alegando una legítima defensa, evidencia que dicha causa de justificación no surge en forma prístina o palmaria sino que existen dudas debiendo el caso resolverse en la sentencia definitiva en juicio oral.

Consideramos que en estos casos deberá admitirse la solicitud de formalización y la Defensa podrá plantear su teoría del caso en la etapa procesal oportuna.

\section{Conclusiones}

En el presente trabajo se analizó la génesis de las modificaciones introducidas por la LUC en el art. 26 del Código Penal y que implicaron cambios sustanciales en la forma de aplicar la legítima defensa como causa de justificación.

Necesariamente esta amplificación -dada fundamentalmente por la introducción de nuevas presunciones- ha repercutido en la práctica en cuanto a la invocación de esta figura por parte de la defensa para plantear oposiciones a la solicitud de formalización por parte de la fiscalía.

Esta cuestión nos planteó la interrogante de si es procedente y viable fundamentar una oposición a la formalización en la existencia de una legítima defensa o si en su defecto, ello es cuestión que en todo caso deberá debatirse en un juicio oral. Nos inclinamos por la segunda opción.

En efecto, existe un reciente pronunciamiento jurisprudencial en el cual el Tribunal de Apelaciones en lo Penal de $4^{\circ}$ Turno señaló que: "(...) la Defensa no recurrió la decisión de formalización, lo que implica limitado a este estadio procesal, que se admitió la existencia de semiplena prueba respecto a la existencia del hecho y a la participación del imputado en el mismo. Esto sin perjuicio de sus alegaciones relativas a la legítima defensa y que ha de probar ésta causal de justificación en juicio oral". (Sentencia N 548/2020 de fecha 1 de octubre de 2020).

Con los argumentos ya señalados nos inclinamos por la segunda opción. Sin embargo, no se soslaya que estratégicamente sea conveniente para la defensa plantear la oposición a la formalización argumentando la existencia de legítima defensa si en etapa posterior de la audiencia se planteará también una oposición a la solicitud fiscal de medida cautelar, por ejemplo, de prisión preventiva.

\section{Bibliografía}

XVIII Jornadas Nacionales de Derecho Procesal, en homenaje al Dr. Fernando Cardinal

Piegas. Octubre 2017, Salto, Uruguay, FCU.

$A A V V$, "Código del Proceso Penal. Reflexiones sobre el nuevo sistema procesal penal en

Uruguay". AA.VV. Coordinadores: Santiago Pereira Campos, Leonel González Postigo, 
Gonzalo Rúa. CEJA - JSCA - INECIP (Instituto de Estudios Comparados en Ciencias

Penales y Sociales). Ed. Universidad de Montevideo. Montevideo 2018.

ALLIAUD, Alejandra, "Audiencias preliminares al juicio oral", Ed. Didot, Bs. As. 2016.

BINDER, Alberto, "El cambio de justicia penal hacia el sistema adversarial. Significado y dificultades." en A.A.V.V. "Código del Proceso Penal. Reflexiones sobre el nuevo sistema procesal penal en Uruguay".

CERDA SAN MARTÍN, Rodrigo, "Manual del sistema de justicia penal", Tomo II, Segunda

edición actualizada, Ed. Librotecnia, Santiago de Chile 2010.

GOMES SANTORO, "Derecho Procesal Penal", Ed. La Ley Uruguay, 2019

LANGÓN, Miguel, Código Penal Uruguayo y Leyes complementarias comentadas. Ed. Universidad de Montevideo. 2017.

LORENZO, Leticia, "Manual de litigación", Colección Litigación y enjuiciamiento penal adversarial. Director, Alberto Binder, Ed. Didot, Bs. As.

LARRIEU, "La actuación del Juez en el Nuevo proceso Penal", en "Estudios Sobre el Nuevo Proceso Penal- Implementación y Puesta en Práctica”, FCU, 2018.

CAIROLI, Milton, "El Derecho Penal uruguayo y las nuevas tendencias dogmático penales", Tomo I, "La Ley - El Delito" FCU, 2º ed. 2001.

MONTANO, Pedro, “Sistema Penal Uruguayo”, Montevideo, marzo 2020.

CAIROLI, Milton, "El Derecho Penal uruguayo y las nuevas tendencias dogmático penales", Tomo I, “La Ley - El Delito" FCU, 2 ed. 2001, Pág. 231.

MALET, Mariana. "Presunciones en el código penal", FCU, Montevideo, 1995, Pág. 160.

Jornada del Colegio de Abogados del 22 de mayo de 2012 aportada por E. Lombardi 